\title{
The contribution of urban green spaces to the improvement of environment in cities: Case study of Chania, Greece
}

\author{
Julia N. Georgi*, Dimos Dimitriou \\ Hellenic Open University, P.O. Box 13680, 10310 Athens, Greece
}

\section{A R T I C L E I N F O}

\section{Article history:}

Received 24 March 2009

Received in revised form

29 October 2009

Accepted 5 December 2009

\section{Keywords:}

Urban climate

Evapotranspiration

Discomfort index

Crop coefficient

\begin{abstract}
A B S T R A C T
This paper investigates how vegetation, mainly through evapotranspiration, affects the improvement of microclimatic conditions in urban areas and, more specifically, it examines the case for the city of Chania in Crete. The objectives of this study are to examine the bioclimatic role of green areas in urban sites as they affect the thermal comfort of residents, and to study the cross-correlation of factors that participate in this process.

To achieve these objectives, we have examined the parameters that contribute to the microclimate of a space and consider how it is influenced by vegetation. In addition, we have analyzed the effect of vegetation with respect to evapotranspiration, and have recorded the existing vegetation of Chania city and the relationship with the geomorphologic and urban characteristics of the city. This has involved calculating the evapotranspiration of various plant species, and collecting measurements at various places in Chania. These studies are designed to determine the cause of the changes of thermal comfort in different parts of the city, and to examine the differentiation of thermal comfort that is observed between different plant species with respect to the evapotranspiration measure that has been calculated for each of them. The intention of this work is to aid efforts to improve the environment of Chania through better planning and the appropriate choice of the species used for planting open spaces. Finally, it is hoped that the results of this work will be of use in planning the environments of spaces in other cities that have similar characteristics.
\end{abstract}

(c) 2009 Elsevier Ltd. All rights reserved.

\section{Introduction}

The development of large, densely populated cities has occurred in the twentieth century in many parts of the planet. The increased urbanization has affected the urban microclimate and continuous to do so today. According to [1] Gianna (2001), the factors that have particular importance in the configuration of an urban microclimate are the topographic configuration of space and the geometry of urban gorges; the distribution and the provision of green spaces and, more generally, all outdoor spaces; the sources of heat and the attributes of exterior surfaces; and the demographic and urban density as well as the layout of buildings. The absence of green spaces is characteristic of most contemporary cities globally, including those in Greece.

\subsection{Urban microclimate}

The urban outdoor spaces have exceptional environmental importance with regard to their contribution to the reduction of

\footnotetext{
* Corresponding author. Tel.: +30 6944373022

E-mail addresses: jgeorgi@tee.gr (J.N. Georgi), dimeren@yahoo.gr (D. Dimitriou).
}

various types of pollution and to the improvement of microclimatic conditions. Furthermore, urban open spaces make positive contributions to human health and well being and they lead to an important contribution to human thermal comfort in exterior spaces.[2,3]. According to Akbari and Taha [4] the factors that affect thermal comfort are(1) solar radiation; (2) temperature of exterior surfaces; (3) air temperature; (4) air humidity; and (5) wind speed. The undesirable attributes of these factors are moderated and counterbalanced by the presence of green spaces. Practical ways to cool urban areas include the use of reflective surfaces (rooftops and pavements) and planting of urban vegetation.

When considering the urban environment it is necessary to have an explicit and precise definition of the significance of thermal comfort. According to the physiological approach $[1,3,4]$ thermal comfort is defined as a situation in which the brain expresses satisfaction with the thermal environment. Because 'satisfaction' tends to be of subjective nature, this definition reflects a wide range of individual levels of comfort. Nevertheless, the physiological factors are important, particularly in the outdoor environment.

The most useful way of expressing the degree of discomfort that prevails in a certain place, at a specific day or time is through the discomfort index [5]. This index is calculated from the air 
temperature and relative humidity, and it has been used in Greece with very satisfactory results [6-8].

According to data from the European Commission, Greek buildings are amongst the most energy consuming in Europe, using $35 \%$ of the energy budget to regulate the temperature indoors [9].

The trees and the open green spaces have multiple uses and their presence in the outdoors makes a major contribution to the saving of energy inside the buildings as well as to the improvement of the microclimate in the urban spaces adjacent to buildings and in urban subareas (Fig. 1). The amount of energy needed for heating and cooling is decreased considerably by the suitable placement of trees around buildings, so that there is much shading from the sun during the summer and as little as possible during the winter. "The improvement of urban microclimate is achieved through the effect that plants have on the balance of temperature and humidity, in the engagement of dust and gases of pollutants and in the regulation of air movement."[10].

Fig. 1 shows that shading can be achieved with the presence of trees, and the resulting advantage of air cooling, without impeding the benevolent exposure to the sun during winter. Deciduous trees offer shade during the summer and the suitable selection of the right species can enhance cooling through 'evapotranspiration,' reducing the temperature by up to $3.1^{\circ} \mathrm{C}$ as mentioned before. During the winter, deciduous trees permit the sun to shine through the branches.

According to [1] Gianna (2001), the attributes of green urban spaces that affect the urban microclimate positively are:

(a) the high rate of absorption of solar radiation;

(b) the low heat capacity and thermal conductivity compared to the structural materials of buildings and urban open spaces;

(c) the reduction of air temperature via transpiration;

(d) the decreased infrared radiation;

(e) the reduction of wind speed around the soil;

(f) the detention of dust and pollutants from the air; and

(g) the sound protection that the presence of trees provides.

During the last twenty years, increasingly "City administrators are more aware of their urban climates and heat islands than they were decades ago, and urban planners and policy makers are now more willing to implement strategies that can modify the urban climate and save energy on the city scale"[4]

According to Dimoudi and Nikolopoulou [11] (2003), vegetation in the urban environment can greatly improve the urban microclimate, as well as mitigate the heat island effect, by reducing summer air temperatures. This effect is noticed not only within the

\section{Summer}

Winter
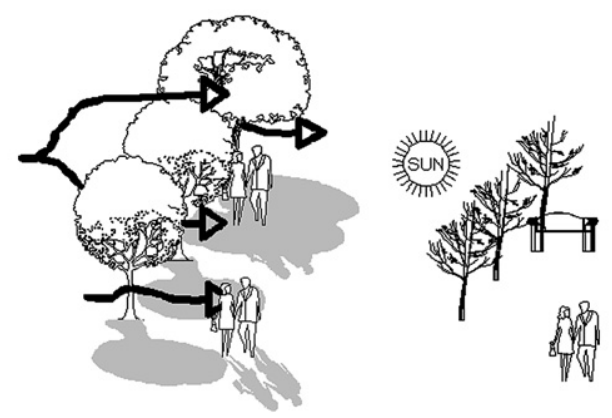

Fig. 1. Shading can be achieved with trees, with the advantage of air cooling, without impeding the sun during winter. Deciduous trees offer shade during the summer and if selected suitably, they can enhance cooling through 'evapotranspiration', reducing the temperature by up to $3.10^{\circ} \mathrm{C}$ as mentioned before. During the winter, trees permit the sun to shine through the branches. boundaries of the green area, where measurements were taken, but extends beyond the park itself, particularly affecting the leeward side of it. Therefore increasing vegetation in the urban context can be an effective way of mitigating the heat island, and benefit urban centres.

Moreover trees offer their beauty, refresh the atmosphere with vapour-transpiration, they decrease pollution, they "absorb" storms and they prevent flooding, but even from an economical point of view, they increase the value of houses that are close to them considerably.

According to Dombrow et al. [13] (2000) and Mansfield et al. [12] (2002) many real estate professionals agree that houses with mature trees are preferred to comparable houses without mature trees. Simpson and McPherson [14] (1998) found that savings of $1.9 \%-2.5 \%$ on cooling costs have been estimated per residential tree, providing a strong financial incentive to choose housing locations with tree cover. According to Aurelia Bengochea Morancho [15] (2003) and the "hedonic technique", the price of the housing relates inversely with the distance that separates it from an urban green space. These findings are in accordance with Bolitzer and Netusil (2000) [16] who concluded that proximity to an open space can have a statistically significant effect on home selling price. Tyrvainen and Miettinen (2000) [17] demonstrated that a $1 \mathrm{~km}$ increase in the distance from the nearest forested area leads to an average $5.9 \%$ decrease in the market price of the dwelling.

As far as environmental variables are concerned, only the distance from a green area is significant. According to the estimates obtained, every $100 \mathrm{~m}$ further away from a green area means a drop of $1800 €$ approximately in the housing price. According to Zoulia et al. [18] (2008) the temperatures between two urban green areas and areas that are surrounded by buildings differ $7^{\circ} \mathrm{C}$ or more during the summer. These results were generated by the measurements that were made by comparing measurements taken in the National Garden of Athens with measurements from selected urban streets with tall buildings along both sides. Therefore the effects of trees in urban spaces, as well as the microclimate that is created under the trees, have been the subject of extensive research.

\subsection{Evaporotransiration}

Trees decrease high temperatures in two ways [19,20,21]:

(a) through shading, with solar radiation collected in the leaves of trees, from where it is absorbed or reflected; and

(b) via evaporation at the local level, by freezing the air because of the utilisation of energy for the transpiration and not for heating.

The most important mechanism through which trees contribute to the reduction of high urban temperatures is evapotranspiration (ET), which is the sum of evaporation and plant transpiration [21]. Evaporation accounts for the movement of water to the air from sources such as the soil, canopy interception, and water bodies. Transpiration accounts for the movement of water within a plant and the subsequent loss of water as vapour through stomata in the leaves. Almost all the water taken in by a plant is lost via transpiration and only a very small fraction is used in the plant. Together, these processes are referred to as evapotranspiration. Evapotranspiration cools the air by using heat from the air to evaporate water [22-24].

Evapotranspiration plays an important role in the water cycle. Plants (Fig. 2) take water from the ground through their roots and emit it through their leaves while water can also evaporate from tree surfaces, such as the stalk, or surrounding soil. Evapotranspiration creates pockets of lower temperature in an urban environment, known as the "phenomenon of oases". It is clear from the literature that evapotranspiration, alone or in combination with 


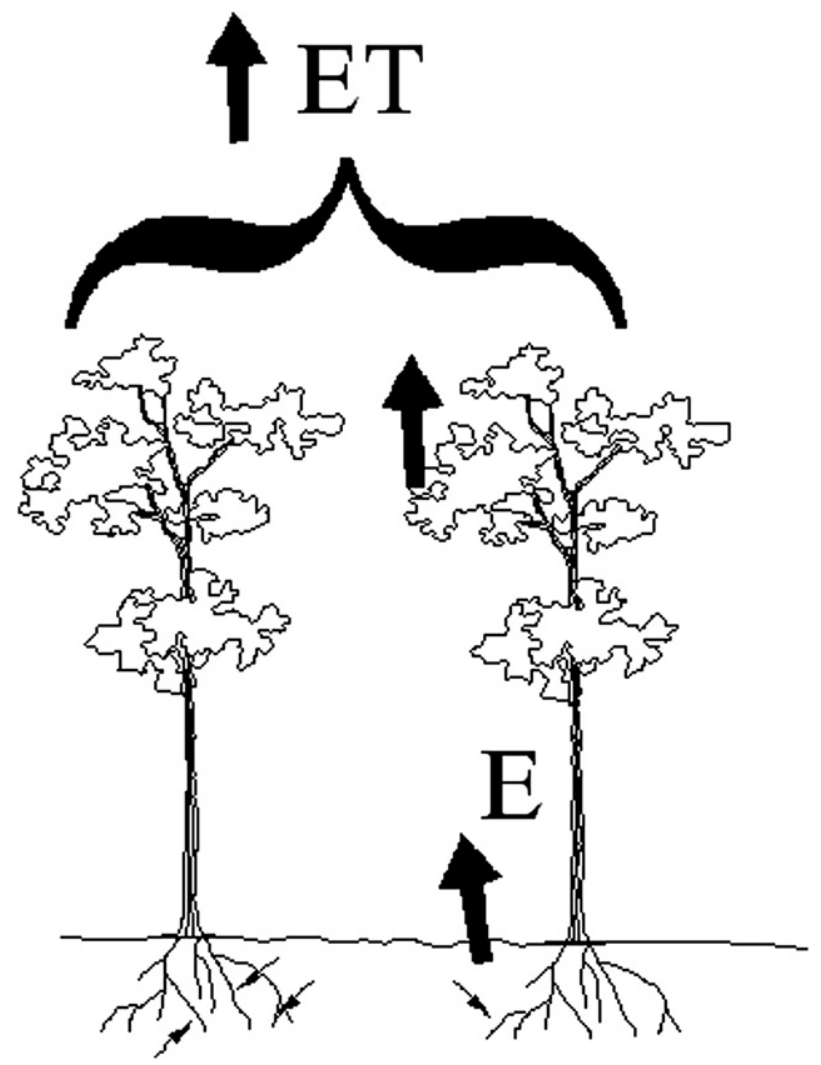

Fig. 2. Process of Evapotranspiration where plants take water from the ground through their roots and emit it through their leaves. Water can also evaporate from tree surfaces, such as the stalk, or surrounding soil.

shading, can help reduce peak summer air temperatures and contributes to the creation of pleasant and comfortable conditions in a city $[23,24]$.

All mechanical air cooling systems "copy" the evapotranspiration operations and functions of trees. However, as it appears in Table 4, trees, in comparison with any other mechanical air cooling system, cost less and last longer.

For example, spraying fans copy the vapour-transpiration processes of trees and they increase the relative humidity of the space, resulting in the increase of thermal comfort. The presence of an awning or shelter is also required for shading in order to achieve thermal comfort. It is obvious that the cost of installation for the shading device should be added to the expenses, if we take into account the consumption of energy and water that is required as well as the cost for maintenance. The planting cost of a tree includes the cost of its purchase, installation, as well as the cost of its maintenance.

Reference evapotranspiration is defined as "the rate of evapotranspiration from a hypothetical reference crop with an assumed crop height of $0.12 \mathrm{~m}$ (4.72 in), a fixed surface resistance of $70 \mathrm{~s} \mathrm{~m}^{-1}$ $\left(70 \mathrm{~s} 3.2 \mathrm{ft}^{-1}\right)$ and an albedo of 0.23 , closely resembling the evapotranspiration from an extensive surface of green grass of uniform height, actively growing, well-watered, and completely shading the ground". In the reference evapotranspiration definition, the grass is specifically defined as the reference crop and this crop is assumed to be free of water stress and diseases. In the literature, the terms "reference evapotranspiration" and "reference crop evapotranspiration" have been used interchangeably and they both represent the same evapotranspiration rate from a short, green grass surface. [25,38].

The reference surface is a grass surface with specific attributes. Crop Evapotranspiration under standard conditions (ETc), is evapotranspiration from disease-free, well-fertilized vegetation, under optimum soil water conditions, without restriction of the availability of water or nutrients under the given climatic conditions $[26,27]$, i.e. real evapotranspiration. ETc depends on the climate and the characteristics of the vegetation, and it can be calculated from climatic data and from parameters such as the thermal resistance, the albedo and the resistance of the atmosphere.

The experimental ratios of ETC/ETo are called crop/plant coefficients $(K c)$, and can be used in the correlation of ETc and ETo according to the equation $E T c=K c * E T o$,where:

$$
\begin{gathered}
E T c=\text { Evapotranspiration } \operatorname{crop}\left(\frac{m m}{d}\right), \\
E T o=E T \text { reference }\left(\frac{m m}{d}\right)
\end{gathered}
$$

$K c=$ Crop coefficient

Differences in the anatomy of leaves, in the characteristics of the stomata, in the aerodynamic attributes and even in albedo cause differences between ETC and ETo under the same climatic conditions. Kc represents the difference of evapotranspiration of any vegetation type compared with that of the reference crop. In the present work, the values of Kc that are used are those given by FAO, and those given by Papazafiriou (1984) [28] specifically for southern Greece. The values of $K c$ for the tree species that were selected for our measurements are: (a) Indian laurel fig (Ficus retusa ssp. nitida), 1.10; (b) stone pine (Pinus pinea), 1.00; (c) Canary Island date palm (Phoenix canariensis), 0.95; (d) bitter orange (Citrus aurantium), 0.60; and (e) olive tree (Olea europaea ssp. europaea), 0.45 .

\section{Materials and methods}

As it was stated earlier, the aim of this study is to examine the bioclimatic role of green areas in urban sites as they affect the thermal comfort of residents, and to study the cross-correlation of factors that participate in this process. The intention of this study is to aid efforts to improve the environment of Chania through better planning and the appropriate choice of the species used for planting open spaces.

\subsection{Study area}

Crete is the biggest island of Greece and ranking 5th in size among islands in the in Mediterranean. Crete is situated in the

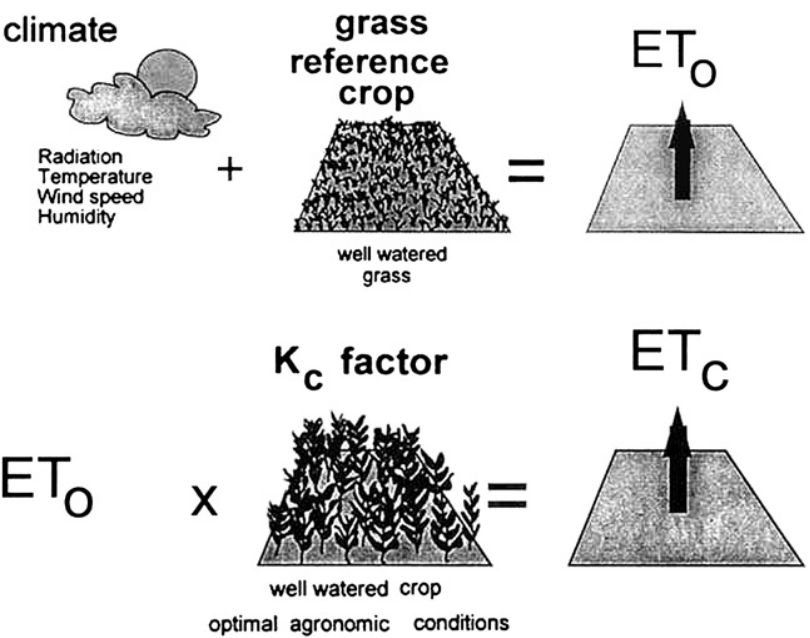

Fig. 3. Reference (ETo), crop evapotranspiration under standard (ETc) [26]. 


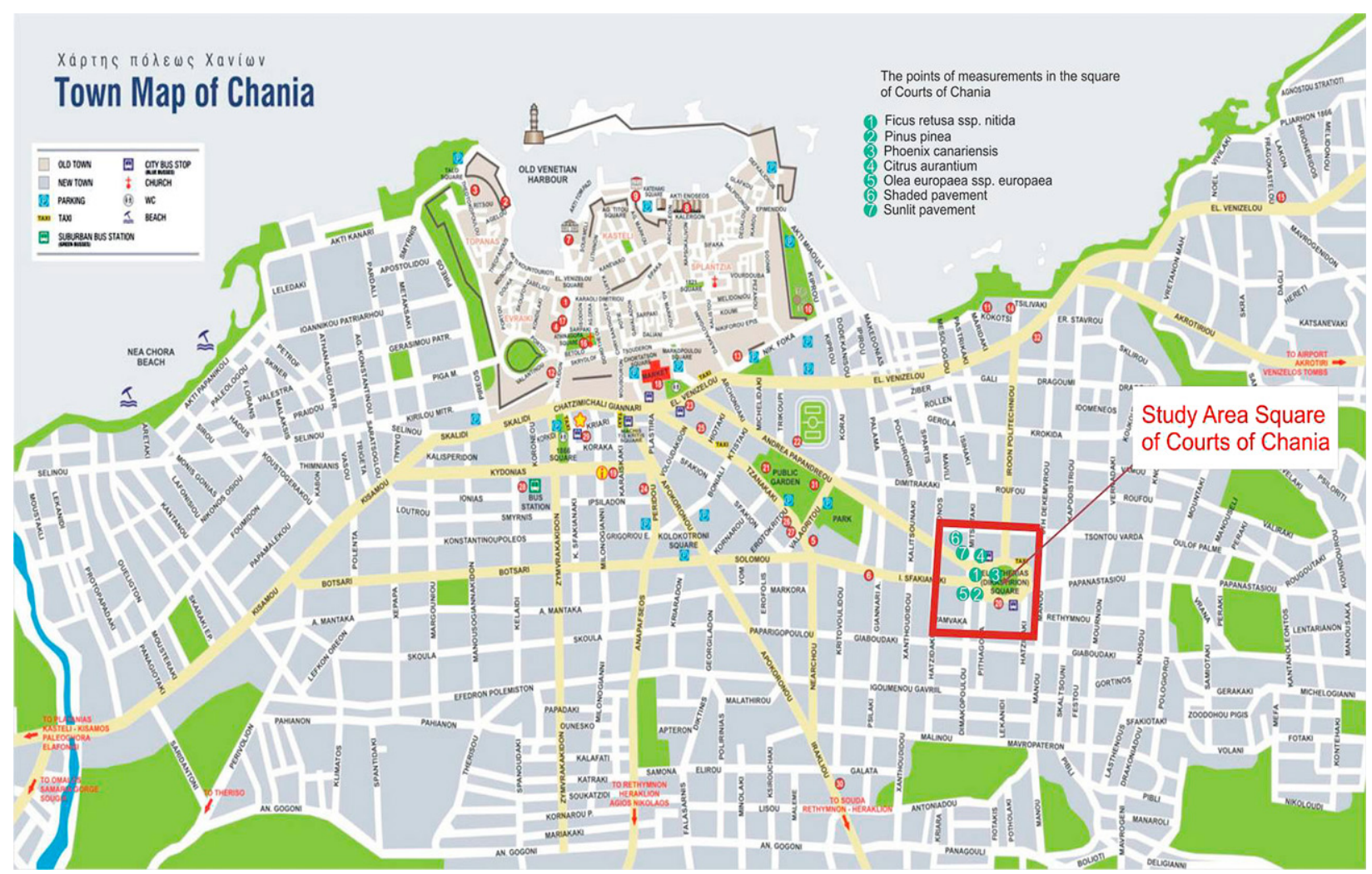

Fig. 4. The points of measurements in the square of Courts of Chania.

southern Aegean Sea, north from the Libykum Sea. Crete belongs to the Mediterranean climatic zone, and it is characteristic of all four seasonal climatic variations. Its climate is a primarily temperate climate. The atmosphere can be quite humid, depending on the proximity to the sea, while the winter is fairly mild. Snowfall is common on the mountains between November and May, but rare at the low lying areas.
The results of this research study as presented in this paper can be used for undertaking a larger scale study of the Mediterranean zone, and can be used as examples for addressing similar problems relative to the planning and the design of the urban environment.

The study area of the present research project is the Municipality of Chania-Crete, a characteristic urban settlement of Southern Greece that occupies an area of 10.862 acres and has a population of

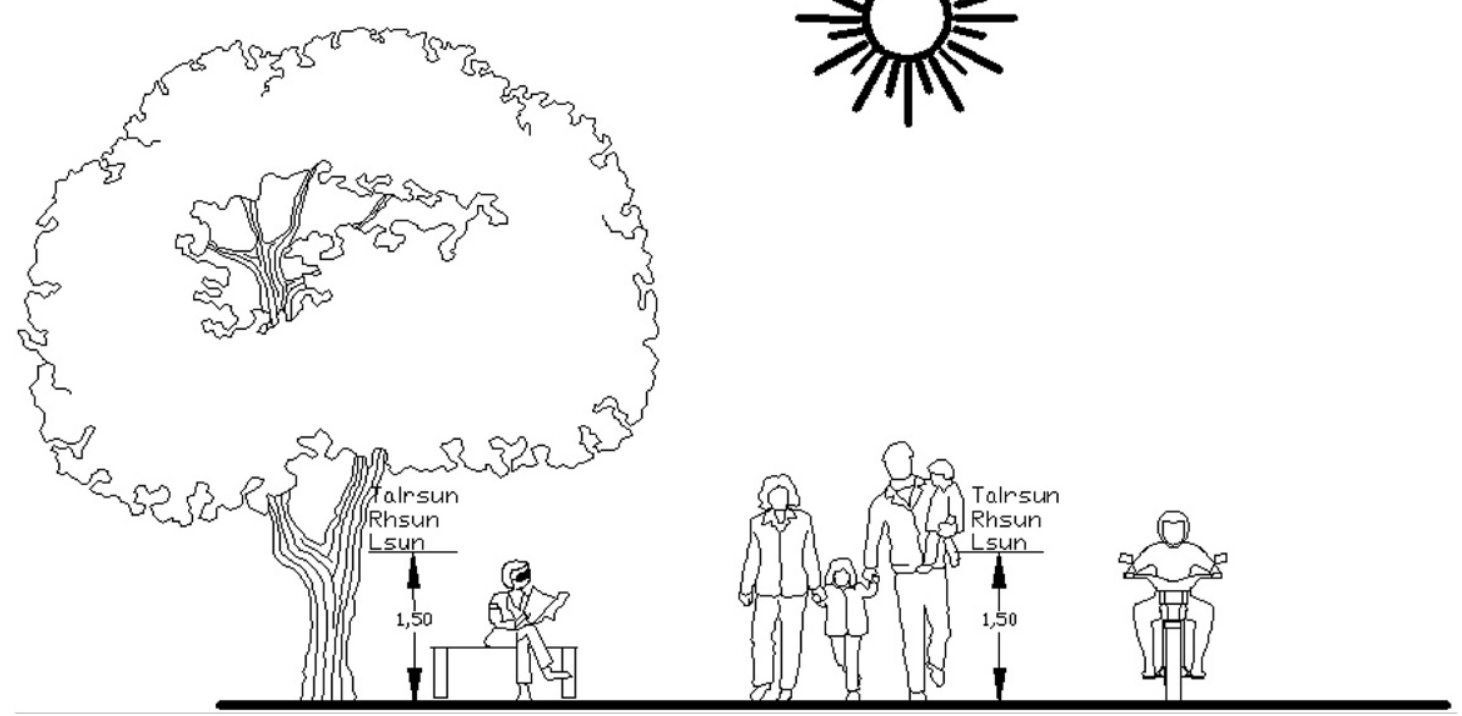

Fig. 5. The measurement taken at the height $1.5 \mathrm{~m}$ above the ground, is about where a person of mean height breathes in. 
Table 1

Information about the measured trees.

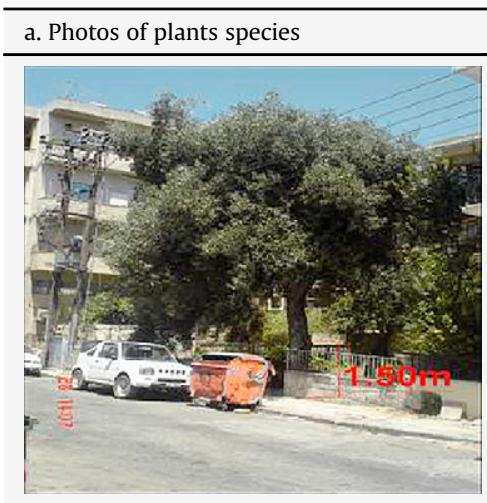

b. Species Characteristics

c. Size of Measurement

d. Height of Measurement

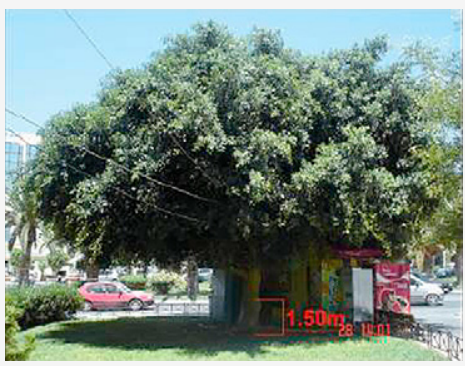

Olea europaea ssp. Europaea

Native of Mediterranean

countries and Greece since

ancient times.

Grows well in all soils, even in

relatively dry, low, gravelly,

calcareous and rocky, there are

enough cracks in the underlying

rock, to develop its roots.
Canopy size: $3 \mathrm{~m}$

$1.5 \mathrm{~m}$ above ground
Ficus retusa ssp. nitida

Native of tropical Asia.

Often cultivated as an ornamental

in warm regions of Greece
Canopy size: $6 \mathrm{~m}$

$1.5 \mathrm{~m}$ above ground
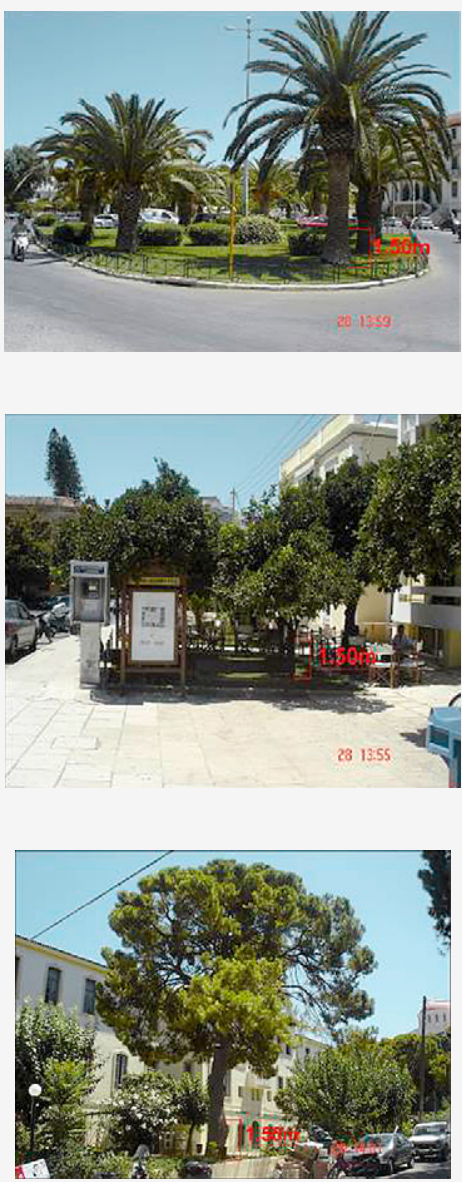

Phoenix canariensis

Plant very suitable for coastal areas, hedgerows and individual positions.
Canopy size: $3.5 \mathrm{~m}$

Canopy size: $2.5 \mathrm{~m}$

Citrus aurantium

Native of tropical and subtropical countries of Asia and the Malay Archipelago.

It develops in nearly all soils and requires no special cultivation tasks. Generally it is the most resistant species to adverse environmental factors from all citrus fruits. More resistant to cold, wet soils to compact and kommiosi which usually affect almost all citrus trees. Suitable for parks.

Pinus brutia

Species of the Mediterranean,

Portugal and the Black Sea.

It is resistant to sea winds and is often grown as an ornamental in coastal areas and parks in cities.
Canopy size: $4.5 \mathrm{~m}$

$1.5 \mathrm{~m}$ above ground 
Table 1 (continued)

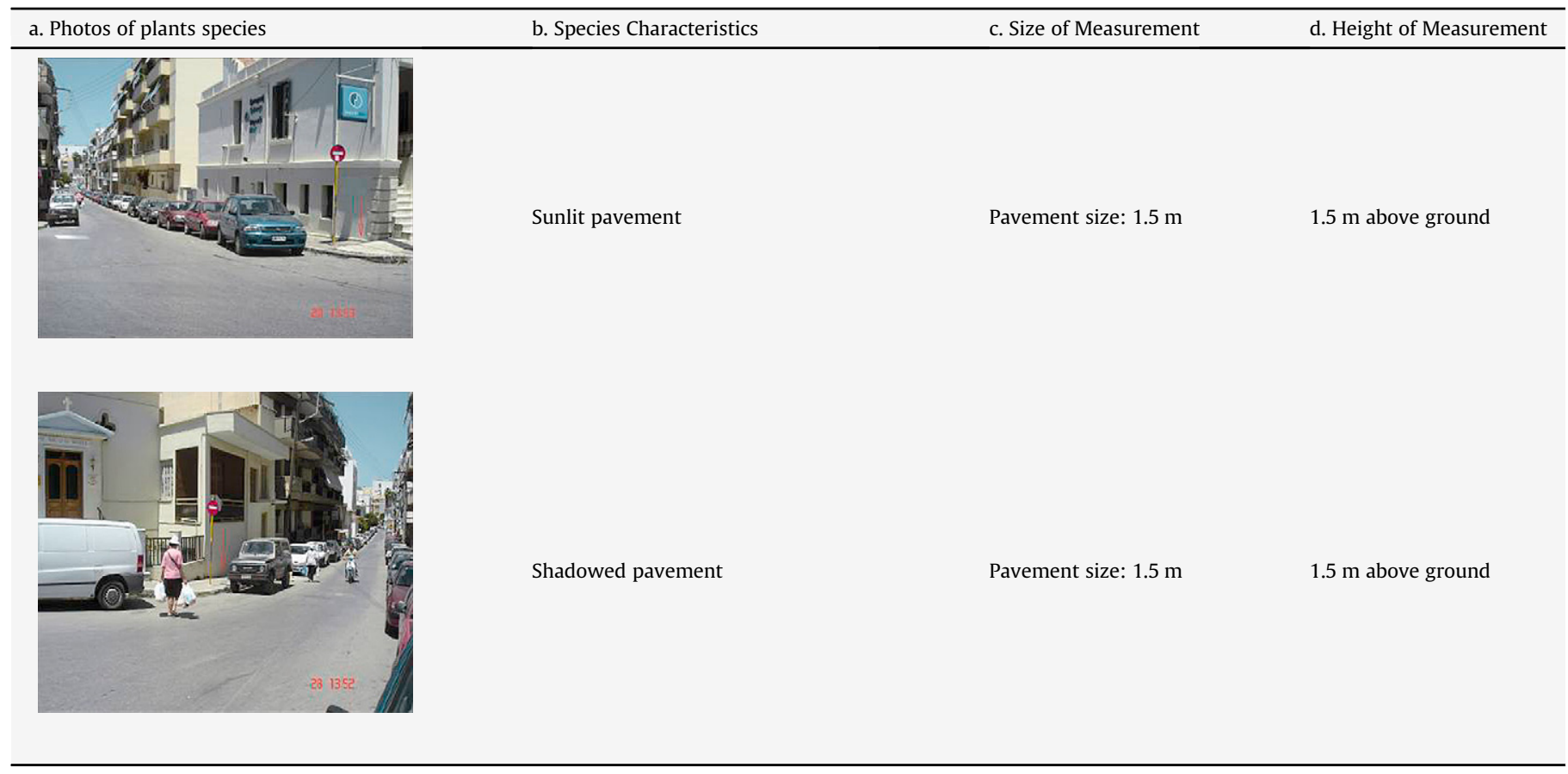

52,000 (Fig. 4) In contrast to the older part of the city, the town plan for the new part of the city was developed on the basis of the Hippodamian system that uses a gridiron street structure. The climate is Mediterranean, with a yearly mean temperature of $18.9^{\circ} \mathrm{C}$ and a long dry period (5-6 months). Fig. 3 shows the points of measurements in the square of Courts of Chania.

Chania lies between Leyka Mountains and the Cretan Sea, above the ruins of ancient Kydonia, bearing the same name as the gulf. The wider region of the city of Chania covers the bigger part of good agricultural land that is found in the northern prefecture and presents a variety in its natural characteristics. The region basically belongs to four basins flowing from Kladissos river, resulting in a limited drainage area, water quantity and high humidity.

The city of Chania serves as a major regional centre for its wider region. Inside the limits of the municipality there are still large size agricultural areas. The largest percentage of these areas is related to the cultivation of olive trees as well as citrus trees (lemons, orange and mandarins), and grapevines. In addition seasonal cultures include mainly horticultural activities.

The city of Chania is characterized by the existence of Mediterranean forests of coniferous trees at Agios Matthaios, Prophitis Ilias and Prevantorio, and areas mainly at the outskirts of the city. The presence of an extensive arboricultural land in the region forms a "green ring" around the city. Areas of substantial cultivations, as well as other agricultural and horticultural uses continue to exist inside the limits of the municipality. Moreover the limitation in quality and quantity of green areas inide the city is the main problem.

Table 2

Kc, Mean ETo and ETc of each examined species.

\begin{tabular}{llll}
\hline Species & Kc & Mean ETo & ETc \\
\hline Olea europea & 0.45 & 6.27 & 2.82 \\
Citrus aurantium & 0.60 & 6.27 & 3.76 \\
Phoenix canariensis & 0.95 & 6.27 & 5.96 \\
Pinus Pinea & 1.00 & 6.27 & 6.27 \\
Ficus nitida & 1.10 & 6.27 & 6.90 \\
\hline
\end{tabular}

\subsection{Description of the methodology}

The methodology we used consisted of the following steps and procedures:

1. Identify urban microclimate study parameters used for the study.

2. Determine the particular values associated with each parameter.

3. Undertake measurements and record values at selected study locations.

4. Analyze the statistic methods.

\subsubsection{Study parameters}

Because the focus of this study is the improvement of the urban microclimate in Chania, we first had to determine the values of the following parameters that were used in the present work: (a) tree species, (b) air temperature, (c) relative humidity, (d) wind speed, (e) ETo, (f) ETc for each tree species, (g) DI Discomfort Index in ${ }^{\circ} \mathrm{C}$, (h) the percentage reduction of the temperature and Discomfort Index in the shade of each tree compared with the plant-free micro-environments where the measurements were made.

\subsubsection{Determination and recording of values}

The recording of values for these parameters was done between 8 and 30 June 2005 for a sixteen day period in order to monitor the changes of the climatic factors during June, when there is a significant contribution to coolness from green spaces to coolness.

Table 3

Values of discomfort index (DI; in ${ }^{\circ} \mathrm{C}$ ) and scales of discomfort [32].

\begin{tabular}{lll}
\hline Feeling of discomfort & & DI $\left({ }^{\circ} \mathrm{C}\right)$ \\
\hline 1 & None & $<21$ \\
2 & $<50 \%$ of the population & $21-24$ \\
3 & $>50 \%$ of the population & $24-27$ \\
4 & Most of the population & $27-29$ \\
5 & Everyone & $29-32$ \\
6 & Phases of medical alarm & $>32$ \\
\hline
\end{tabular}


Measurements were made at midday, and the effects are most obvious in the interval from 13:30 to 15:00 p.m. The measurements did not take place on days when the sky was Nubes Dispersa or on days when there was great wind speed, because it was not possible to make measurements in values on sunlit surfaces.

The parameters that have the most influence on evapotranspiration were taken to be constants, in order to determine the values of measurements that emanate from the difference in evapotranspiration associated with each tree species. We selected summertime as a season because the weather parameters such as solar radiation, air temperature, relative humidity and wind speed, do not show marked fluctuations.

Also, the location of the tree species was selected to avoid hypsometric difference or great distances between them and changes in the microclimate from the effect of other exogenic factors.

For all the species included in the measurements, the shape of the shade (on the ground) was uniform, and the area that was shaded was not covered with building materials but with plants grass or ground. The criteria used to select the items to make the recording of measurements are as follows:

a) a good fit in the urban environment of the city

b) The high frequency with which they appear, especially the olive and citrus fruit trees and therefore have greater contribution to the microclimate

c) The values of vegetable factor $(\mathrm{Kc})$ of each species are typical, and quite large differences between them, to investigate more clearly whether the degree of contribution of each species is proportional to the microclimate of the plant and by extension rate and the price of evapotranspiration of any kind.

\subsubsection{Measurements}

We measured the shade afforded by the following tree species: (1) Ficus nitida, (2) P. pinea, (3) P. canariensis, (4) C. aurantium, (5) Olea europea, both (6) for ground shaded by buildings, and (7) for sunlit ground. The measurements of temperature $\left( \pm 1^{\circ} \mathrm{C}\right)$, relative humidity $( \pm 3 \%)$ and wind speed $( \pm 3 \%)$ were made simultaneously with a Speedtech Instruments SKYMASTER, model SM-28, pocket weather meter. Overall, there were repeated daily measurements in three climatic parameters in five different vegetation types and two different points of open urban spaces. During the period from June 8 to June 30, 2005, a record 16 days, 224 measurements were made.

The wind speed was not used in processing the results. It was however necessary to make the measurements because only when they gave minimum values we could continue in the other measurements. Variations in wind speed affect the aerodynamic resistance, and hence plant factors. The vegetable factor (Kc) for many species increases with increasing wind speed and reduce the relative humidity.

Typical values of plant inputs given by the literature and used in this work, refer to specific climatic conditions, in terms of daily minimum relative humidity and wind speed [28]. All the species that have been measured were local species that are mainly used along roads and parks of the city. It has been given below some specific information as: (a) photos of the species and the areas that are measured, (b) main characteristic of the species, (c) canopy sizes of the species and (d) height of the species that are measured.

The research includes taking measurements in the field, and analysis of experimental data, which has shown the contribution of green spaces, via evapotranspiration, to the improvement of the urban microclimate.

Fig. 5 shows that the measurements are taken at $1.5 \mathrm{~m}$ above the ground, and is approximately the level where a person of mean height breathes in.
Table 4

Comparison of cost installation and duration of life between trees and devices.

\begin{tabular}{|c|c|c|}
\hline $\begin{array}{l}\text { Cost of tree with 35lt of } \\
\text { earth purchase - } \\
\text { installation } \\
\text { - maintenance) }\end{array}$ & $140,55 €$ & $\begin{array}{l}\text { Duration of life: } \\
\text { over a century }\end{array}$ \\
\hline $\begin{array}{l}\text { Installation of exterior } \\
\text { system of air cooling } \\
\text { (fan of spraying) }\end{array}$ & $900-1000 €$ & $\begin{array}{l}\text { Duration of life: } 10-15 \\
\text { years (according to use) }\end{array}$ \\
\hline $\begin{array}{l}\text { Installation of glass } \\
\text { panes of low emission }\end{array}$ & $150-180 € / \mathrm{m} 2$ & $\begin{array}{l}\text { Duration of life: } 15-20 \\
\text { years (according to use) }\end{array}$ \\
\hline $\begin{array}{l}\text { Installation of awning } \\
\text { with buckram that } \\
\text { provides air cooling as } \\
\text { well as shading }\end{array}$ & $120 € / \mathrm{m} 2$ & $\begin{array}{l}\text { Duration of life: } 10-15 \\
\text { years }\end{array}$ \\
\hline
\end{tabular}

In the present work, ETo is calculated with a method that has been validated for meteorological data by Hargreaves (1985) [29], who has shown very good results on a worldwide scale. The method gives very reliable results for the prefecture of Chania, as is shown by comparison of seven methods of calculation described by Bertaki (2001) [27]. The comparison was made for results obtained by the following methods: (1) modified Penman, (2) initial Penman, (3) Penman-Monteith, (4) Hargreaves, (5) Thornthwaite, (6) Turc, (7) modified Blaney-Criddle, and (8) Evaporometer (Evaporation counter)

ETo is calculated according to the following relation [29]:

ETo $=0.0023 R a(T o+17.8) T D^{0.5}\left(\frac{m m}{d}\right)$

where $R a=$ solar radiation $\frac{m m}{(d)} T o=(T \max +T \min ) / 2$, is the sum of the mean of the maximum temperature $T \max$ and the mean of the minimum temperature $T \min \left({ }^{\circ} \mathrm{C}\right)$ divided with 2 , and $T D=T \max -T \min$, is the difference between $T \max$ and $T \min \left({ }^{\circ} \mathrm{C}\right)$.

We used the meteorological data for the last 11 years in order to calculate the mean from the data compiled by the meteorological station of Institute of Olive Tree and Sub-tropical Plants, which is close to our study area.

We calculated the mean of ETo, for June according to the method described by Hargreaves:

ETo $=6.27\left(\frac{m m}{d}\right)$

Evapotranspiration Crop (Etc) is calculated from ETo with $K c$, which expresses the differences in the evaporation of all species. Papazafiriou (1984) [28] reported the values of $K c$ specifically for Southern Greece. The values for the species that were selected for our measurements are: Ficus nitida, 1.10; P. pinea, 1.00; P. canariensis, 0.95; C. aurantium, 0.60; Olea europea, 0.45 . Hence ETc is calculated by the relation (Table 1 ):

Table 5

Three different cooling installations in $100 \mathrm{~m}^{2}$ of space.

\begin{tabular}{cllll}
\hline & Size & Items & Cost & Benefits \\
\hline $\begin{array}{c}\text { Tree with } \\
\text { ball of } \\
\text { earth 351 } \\
\text { (Fig. 11) }\end{array}$ & $100 \mathrm{~m}^{2}$ & 8 & $1128 €$ & $\begin{array}{l}\text { Solar } \\
\text { protection, } \\
\text { air cooling, } \\
\text { aesthetic } \\
\text { enjoyment } \\
\text { fan of }\end{array}$ \\
$\begin{array}{c}\text { spraying } \\
\text { (Fig. 12) }\end{array}$ & $100 \mathrm{~m} 2$ & 4 & $4000 €$ & Air cooling \\
$\begin{array}{c}\text { awning } \\
\text { (Fig. 13) }\end{array}$ & $100 \mathrm{~m}^{2}$ & $1 \times 100 \mathrm{~m}^{2}$ & $12000 €$ & $\begin{array}{l}\text { Shading and minimal } \\
\text { reduction of } \\
\text { temperature }\end{array}$ \\
\hline
\end{tabular}

*the costs were calculated in accordance with prices that are presented in Table 4. 
Table 6

Results of analysis of variance: Analysis of variance of temperature's measurements by one factor.

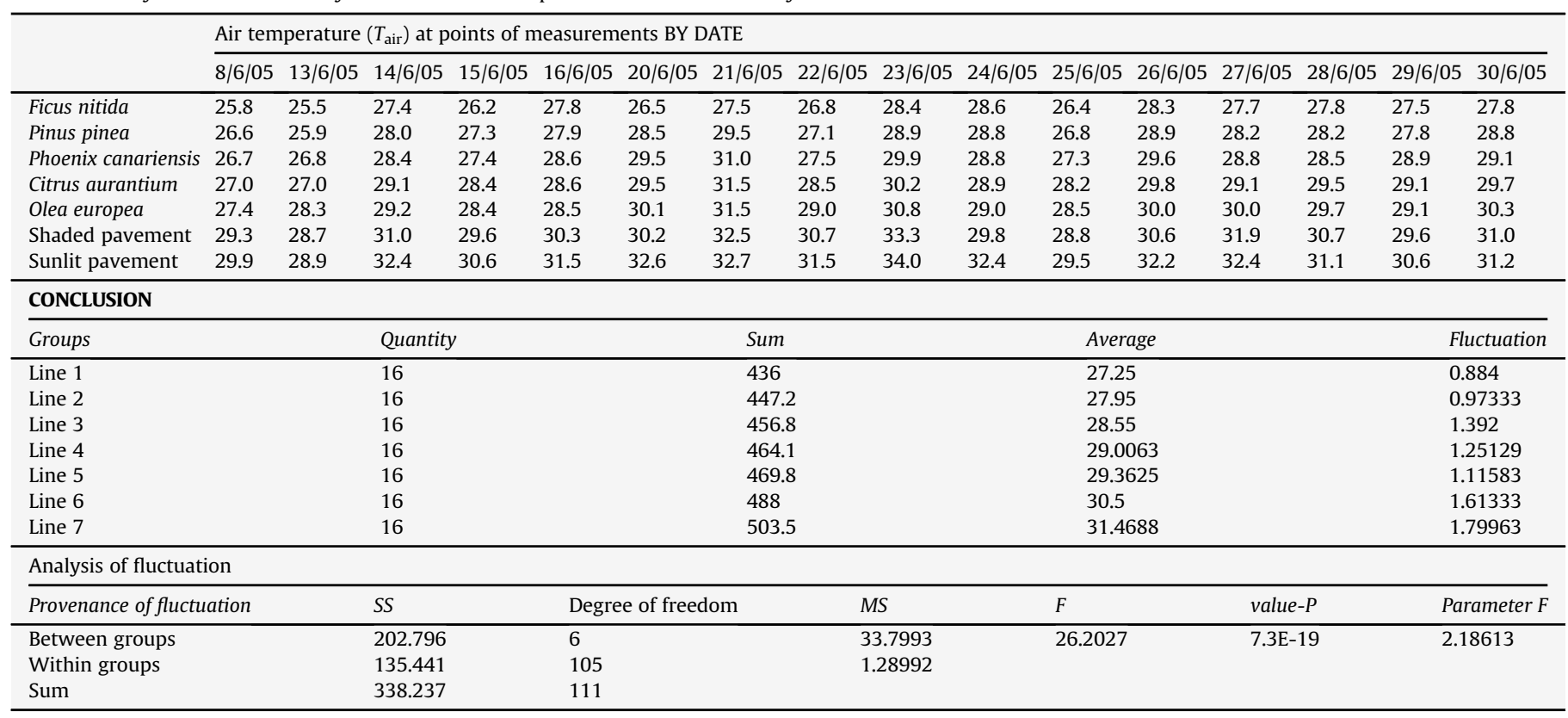

\section{$E T c=E T o^{*} K c$}

Table 2 below shown crop/plant coefficients (Kc), Mean Reference evapotranspiration ETo and crop evapotranspiration under standard conditions (ETc) of each examined species Tables 4 and 5.

$D I$ for all the dates and for all the places where measurements were taken was derived from the relation:

$D I=T E M-0.55(1-0.01 \mathrm{HUM})(\mathrm{Tem}-14.5)^{\circ} \mathrm{C}$

where $D I$ is in ${ }^{\circ} \mathrm{C}$, TEM is the air temperature in ${ }^{\circ} \mathrm{C}, H U M$ is relative humidity as a percentage. Also we calculated the percentage reduction of $D I$ that is achieved in the shade of each tree compared with both micro-enviroments (the one of the sunlit pavement and the other of shaded pavement). This value is termed $d D I \%$, which is calculated from the relations:

$$
\begin{aligned}
& \mathrm{dDI}_{\text {sh. }} \%=\left(\mathrm{Dlsh}_{\text {sh.pav }}-\mathrm{DI}_{\text {sh.tree }}\right) / \mathrm{Dl}_{\text {sh.pav. }} \times 100 \text { and } \\
& \mathrm{dDI}_{\text {sun. } \%}=\left(\mathrm{Dl}_{\text {sun.pav. }}-\mathrm{DI}_{\text {sh.tree }}\right) / \mathrm{Dl}_{\text {sun.pav. }} \times 100
\end{aligned}
$$

Finally, we calculated the percentage reduction of temperature that is achieved in the shade of each tree compared with both microenviroments (the one of the sunlit pavement and the other of shaded pavement). This value is termed dTEM\%, which is calculated from the relations:

Table 7

Results of analysis of variance: Analysis of variance of relative humidity by one factor

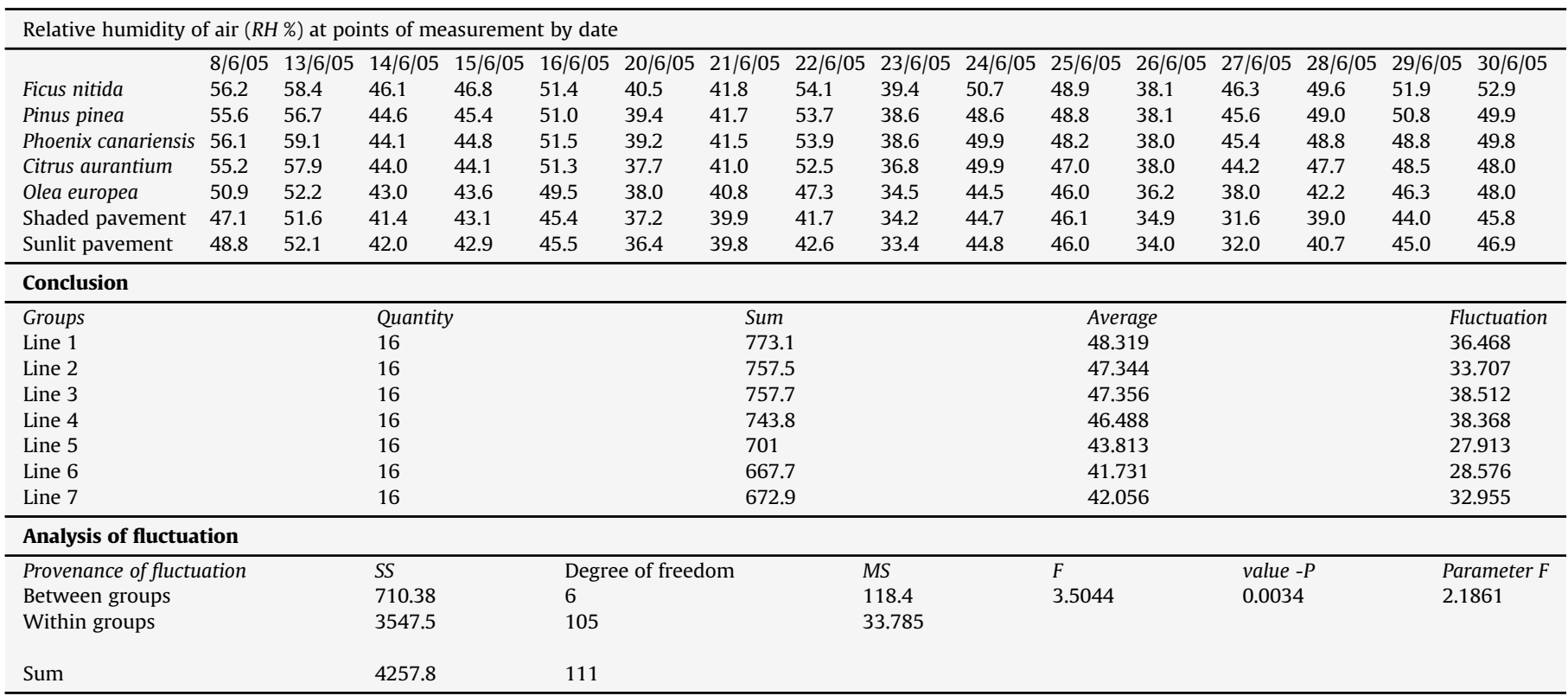


Table 8

Results of analysis of variance: Analysis of variance of DI measurements by one factor.

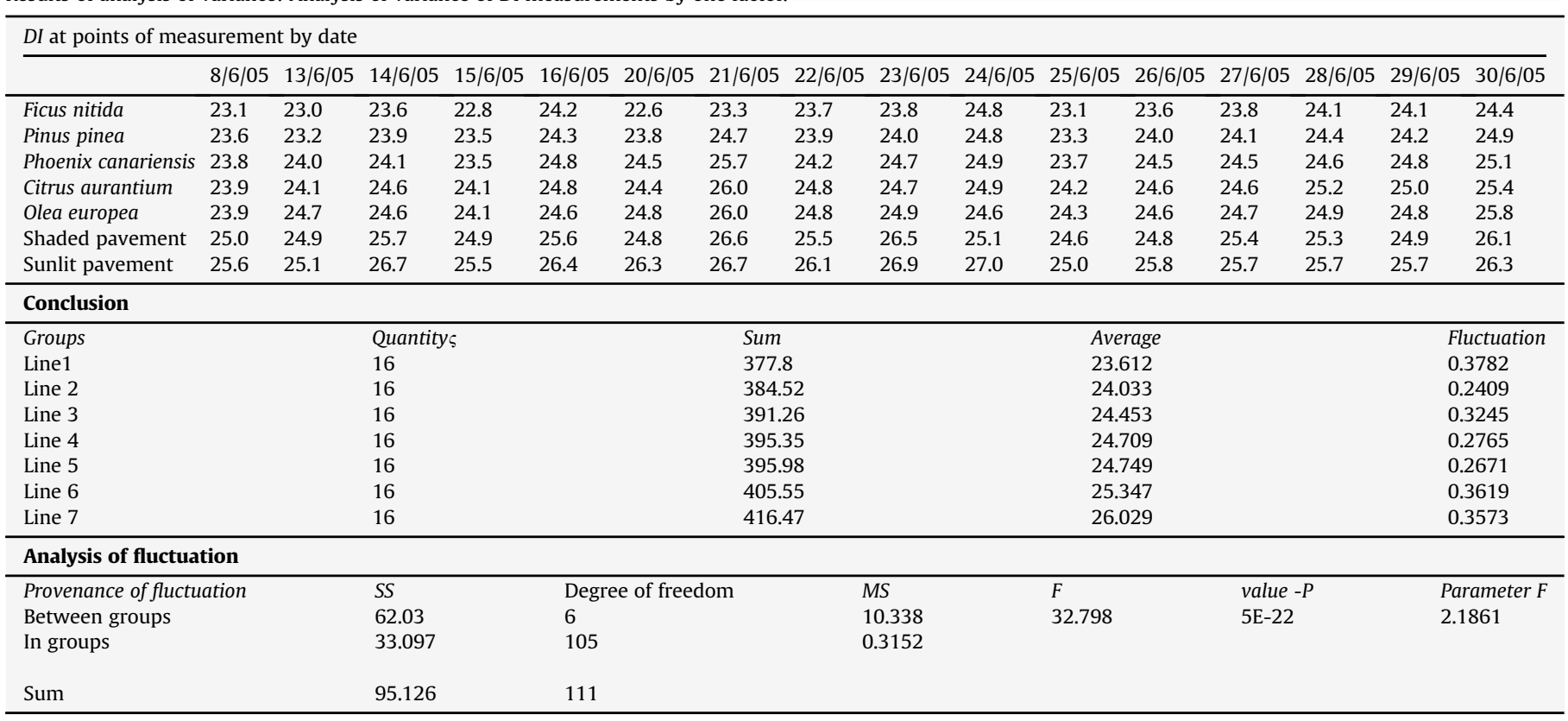

$\mathrm{dTEM}_{\text {sh. }} \%=\left(\mathrm{TEM}_{\text {sh.pav. }}-\mathrm{TEM}_{\text {sh.tree }}\right) / \mathrm{TEM}_{\text {sh.pav. }} \times 100$ and

$\mathrm{dTEM}_{\text {sun. }} \%=\left(\mathrm{TEM}_{\text {sun.pav. }}-\mathrm{TEM}_{\text {sh.tree }}\right) / \mathrm{TEM}_{\mathrm{H} \text { sun.pav.. }} \times 100$

The use of DI values and temperature in this work does not represent a description of $D I$ that people sense, but the calculation of the percentage reduction of comfort that is achieved in the shade of a tree, even if it is not always perceptible by people (e.g. in the case of a small percentage reduction); and we examined the differences of reduction between species.

\subsubsection{Analysis of the statistic methods}

Statistical analysis was used to evaluate the importance of the results obtained in this study.

We used one-way analysis of variance (ANOVA) to examine differences between temperature, relative humidity and $D I$ in the different micro-environments. This statistical technique will help

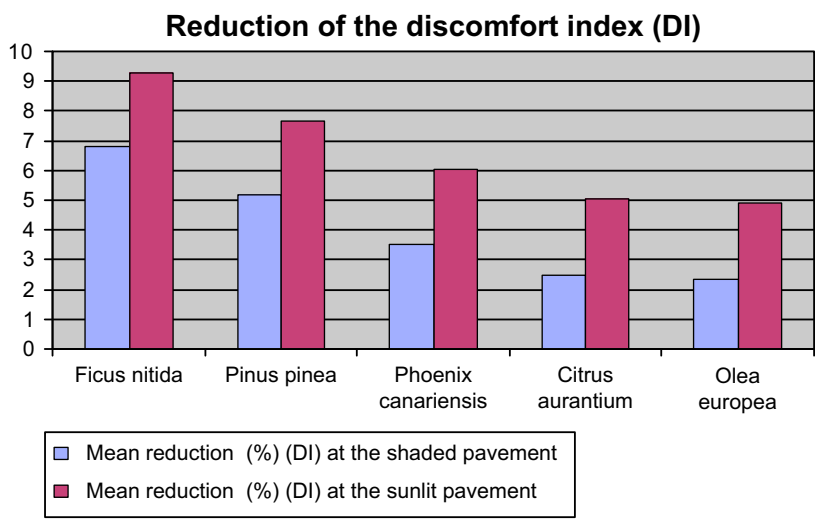

Fig. 6. Reduction of the discomfort index of each species. to quantify how much the observations of each category are altered between them, as well as differences in the mean values between the categories. First, we investigated whether there were statistically significant differences between the means of measurements in the different micro-environments. The analysis for the three parameters was done with Microsoft Excel software. We used Student's $t$-test to examine differences between paired means.

In order to particularize the diversity of prices of factors that were elected between the micro-environments, a comparison of Means at pairs should be accomplished.

This technique allows us to investigate the statistical significance of any differences between values measured in the two micro-environments.

The other way of analysis was the use oft-test. The use of the $t$ test for paired data has the advantages that the measurements are made under the same conditions, and this test is able to reveal significant differences with confidence. The analysis was done with the computer package SPSS (Tables 9-11).

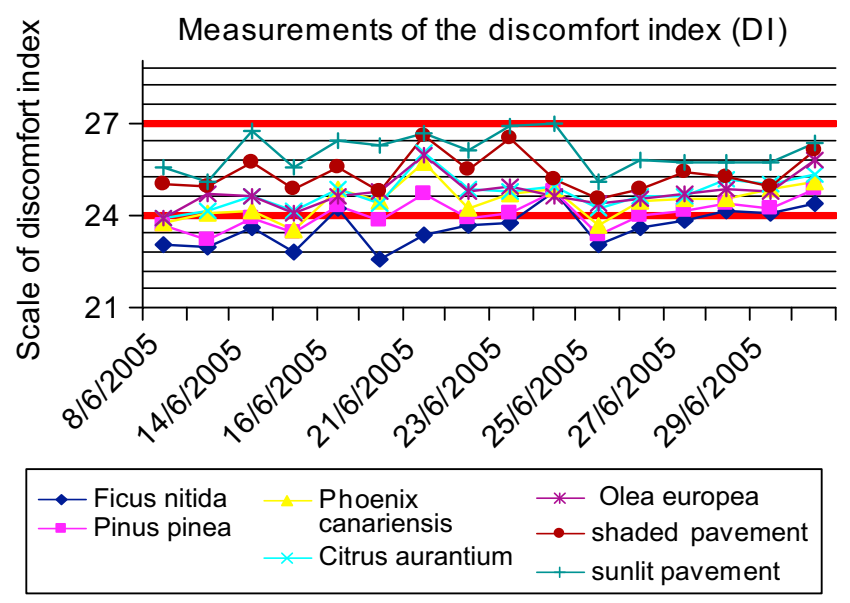

Fig. 7. Measurements of the Discomfort index (DI) at several days for each species on shade and sublit pavements. 


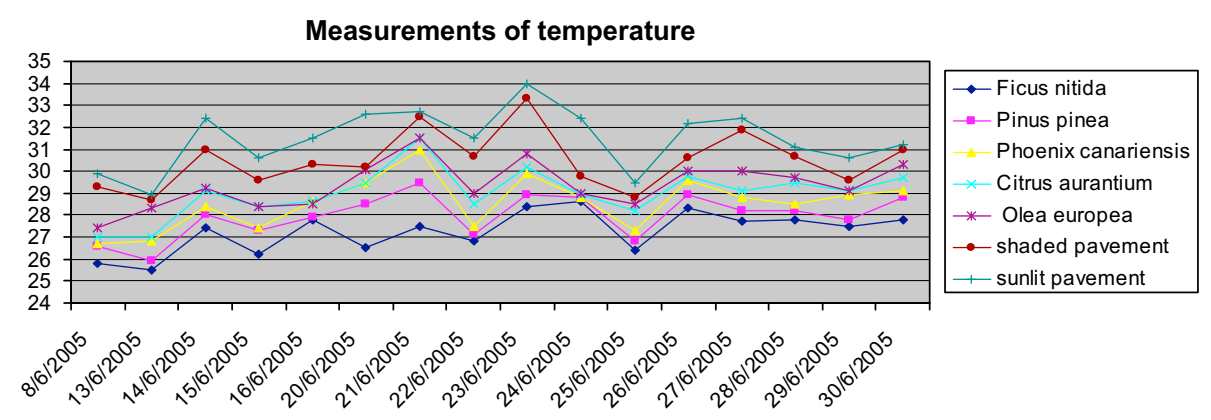

Fig. 8. Measurements of temperature of each at several days for each species on shade and sublit pavements.

\section{Results}

The values of temperature and DI measured in the shade of plants are lower in all cases than that of sunlit pavements, with a mean reduction of $3.1^{\circ} \mathrm{C}$. These measurements agree with those obtained by other researchers, e.g. Taha et al. (1988) [30] reported "measurements in the suburbs of Sacramento in regions where mature trees exist showed that the temperature of air under the trees foliage was $1.7-3.3{ }^{\circ} \mathrm{C}$ lower concerning regions where trees do not exist "; Parker (1989) [31] reported the results of a study in Miami (Florida) "the medium reduction of air temperature at the duration of summertime is $3.6^{\circ} \mathrm{C}^{\prime}$; and Akbari et al. (1992) [4] reported "similar studies in the Sacramento and in the Phoenix showed that with increase of trees at $25 \%$ it can decrease itself the temperature the summertime at $3.3-5.6^{\circ} \mathrm{C}$ ".

In the present study, there was no difference in the values of temperature or DI between the micro-environments of planted and plant-free areas. However, there is a difference in the values that are observed for the different species of tree. The temperature and $D I$ values observed in the micro-environment of trees were ranked in the descending order olive $>$ bitter orange $>$ palm $>$ pine $>$ fig.

The highest values were found in the shade of drought-tolerant evergreen Mediterranean types that, via evapotranspiration, provide an atmosphere with low relative humidity, represented here by the olive tree, while the lowest values were found in the shade of the tropical types that provide an atmosphere via evapotranspiration with high relative humidity, represented here by the fig. For the same date and roughly the same time of day, measurements of temperature and DI separated by a distance of $\sim 10 \mathrm{~m}$ can show appreciable differences. The highest levels of relative humidity were recorded in the shade of fig trees. The mean values of relative humidity were found in the descending order fig $>$ palm $>$ pine $>$ bitter orange $>$ olive. The values of relative humidity were, as expected, lower in areas with no planting; i.e. in the regions of sunlit and shaded pavement. Between the different types of tree, we observe that those associated with the higher values of relative humidity are those with the higher values for evapotranspiration calculated as described above, and the values decrease with the decrease of the calculated mean value of evapotranspiration. These results constitute direct confirmation of the validity of the calculation method described by Hargreaves.

Also, from the results for the percentage reduction of temperature that is achieved by the shade of each tree compared with the two plant-free micro-environments, it is observed that the mean reduction of the measurements for areas with planting compared with those of sunlit pavement is around 9.6\%. These differences of temperature agree with the data reported by others, e.g. Georgi (2000) [7], Georgi \& Zafiriadis (2006) [8] calculated the mean percentage of reduction of temperature (Tair\%) as 9.5\%. The mean reduction of DI in all measurements for areas with planting compared with those of sunlit pavement is around 6.6\%, and Georgi (2000) [7], Georgi \& Zafiriadis (2006) [8] reported a value of around $5.6 \%$.

As is shown by the statistics, important differences exist among the various micro-environments concerning the environmental parameters (temperature, relative humidity and Discomfort Index.) Because it is important to know if any of the examined species influences considerably the abovementioned environmental factors, the effect of all species of the three examined parameters will be evaluated.

The results of ANOVA of the differences among the microenvironments were as follows: For temperature, $F=26.203$ $(P=7 \mathrm{E}-19)$; for relative humidity, $F=3.504(P=0.0034)$; and for $D I, F=32.798(P=E-22)$. All of these values reveal statistically significant differences among the micro-environments.

Statistically effectively significant differences exist among the Mean measurements of temperature, the relative humidity and the Discomfort Index in the different micro-environments.

The use of Student's $t$-test for comparison of paired means (21 pairs) for each from the three parameters yielded the following

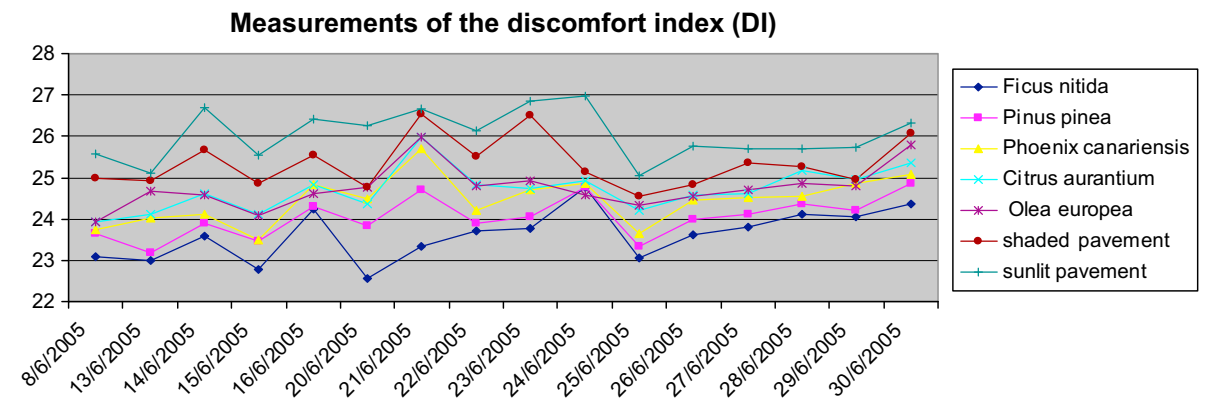

Fig. 9. Measurements of discomfort index (ID) of each at several days for each species on shade and sublit pavements. 


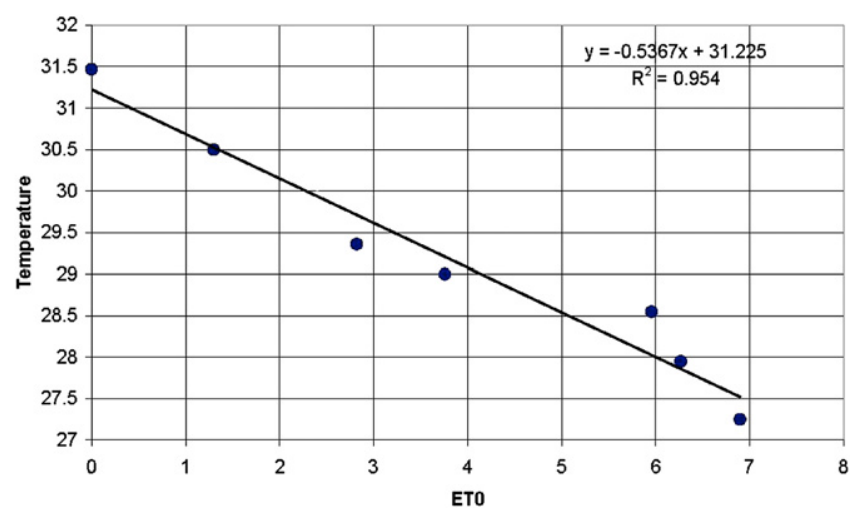

Fig. 10. The comparison of the value of evaporation (ET) in different tree species with the temperature $(\mathrm{T})$ that develops under each trees.

results. The micro-environment of the fig tree (tropical type) was statistically significantly different from all other micro-environments examined. This is the species with higher values of relative humidity and that affords the greatest reduction of temperature and DI compared to all the other species in this study. They are ranked in the descending order pine (coniferous) $>$ palm (subtropical type) $>$ bitter oranges (subtropical type $>$ olive (Mediterranean type). Consequently, with respect to the effect of plants on temperature and $D I$, the most favourable species are those with higher values of relative humidity and evapotranspiration (see table $6-8$ and Figs. $6-8$ ). Therefore Fig. 6 shows the reduction of the discomfort index of each species, Fig. 7 shows the measurements of the Discomfort index (DI) at several days for each species on shade and sublit pavements, and Fig. 8 shows the measurements of temperature of each at several days for each species on shade and sublit pavements. Additionally Fig. 9 shows the measurements of discomfort index (ID) of each at several days for each species on shade and sunlit pavements.

The environment of a shaded pavement always has higher values of temperature and $D I$, and indeed shows a highly significant difference compared with all the environments of plants, although the comparison is always between two shaded sites.

In order to estimate the feeling of discomfort, we determined certain limits, which are given in Table 3.

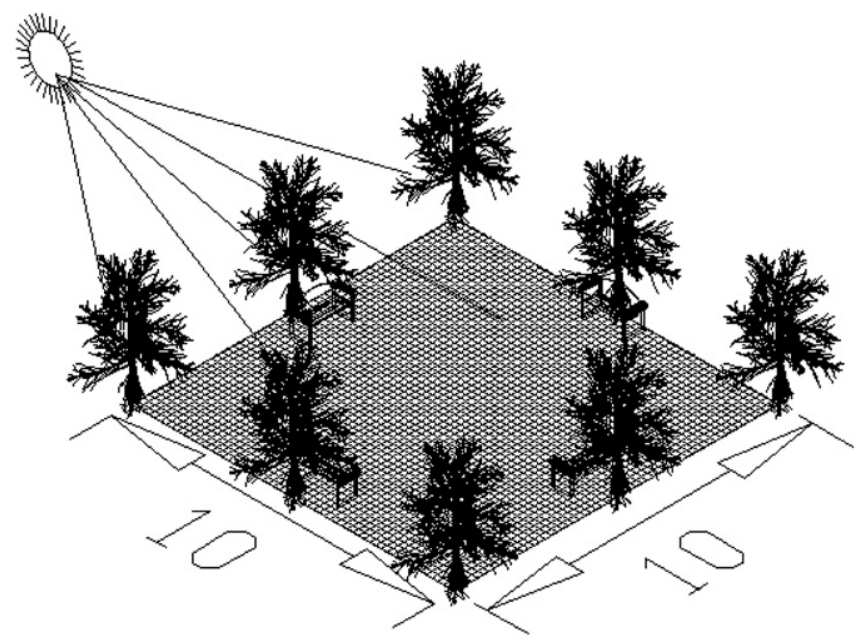

Fig. 11. In a space of $100 \mathrm{~m}^{2}, 8$ trees can be placed, creating a more pleasant environment to the visitor and at the same time providing protection from solar radiation.

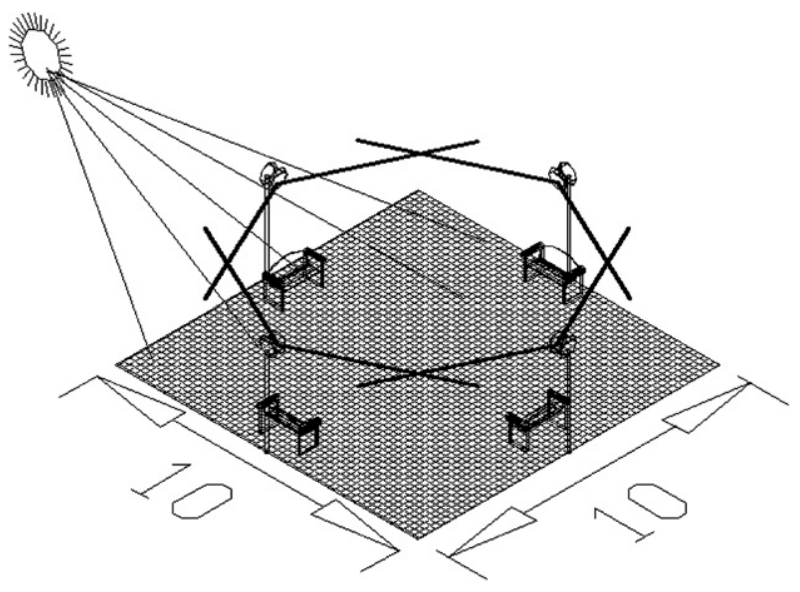

Fig. 12. In a space of $100 \mathrm{~m}^{2}, 4$ spraying fans can be placed, which serve only this space and create a hostile environment without providing some other type of protection.

If we match the $D I$ values of each micro-environment with the scales of feeling of discomfort as shown in Table 3, we can draw the following conclusions. In the season when the measurements were collected, there is no value of $D I<21$ and therefore all values reflect some degree of feeling discomfort. The values that were measured oscillate between the second and third category, where feelings of discomfort are experienced by $<50 \%$ of the population and by $>50 \%$ of the population, respectively. On 24/06/2005 in the environment of a sunlit pavement, the value of $D I$ reached the limits of the fourth category where most of the population feel discomfort.

Table 3 confirms the tendency that was described above according to which the plants with a high value of evapotranspiration offer a more comfortable micro-environment. Thus, the fig (tropical type of tree), via evapotranspiration removes the greatest amount of humidity ( $6.90 \mathrm{~mm} /$ day $)$ and usually creates, with few exceptions, the most pleasant micro-environment, where discomfort is felt by less than $50 \%$ of the population. On the same scale, there is very little difference between the DI values of the fig and of

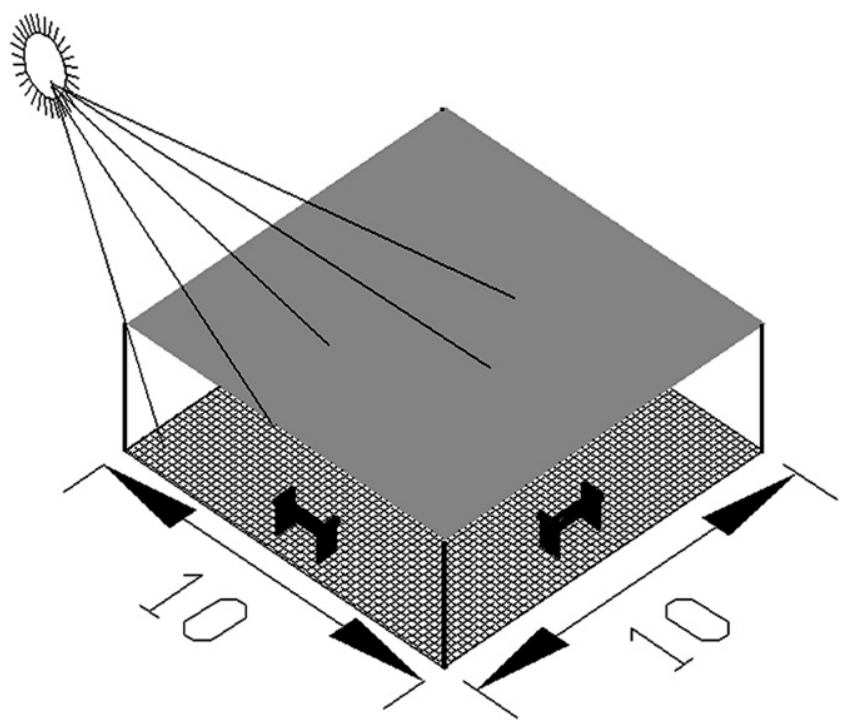

Fig. 13. In a space of $100 \mathrm{~m}^{2}$, an awning that would cover $100 \mathrm{~m}^{2}$ can be installed the cost of which is increased and the only benefit that it offers is the protection from the solar radiation with a minimal reduction in temperature. 
Table 9

Results of comparison between averages by pairs ( $t$-test): Comparison between averages of temperatures by different pairs of micro-environments by the $t$-test.

\begin{tabular}{|c|c|c|c|c|c|c|c|}
\hline & 1. Ficus nitida & 2. Pinus pinea & 3. Phoenix canariensis & 4. Citrus aurantium & 5. Olea europea & 6. Shaded pavement & 7. Sunlit pavement \\
\hline 1. Ficus nitida & $1 /$ & $P=0.049^{* *}$ & $P=0.002^{* * *}$ & $P=0.000^{* * *}$ & $P=0.000^{* * *}$ & $P=0.000^{* * *}$ & $P=0.000^{* * *}$ \\
\hline 2. Pinus pinea & $P=0.049^{* *}$ & II & $P=0.129$ & $P=0.008^{* * *}$ & $P=0.000^{* * *}$ & $P=0.000^{* * *}$ & $P=0.000^{* * *}$ \\
\hline 3. Phoenix canariensis & $P=0.002^{* * *}$ & $P=0.129$ & /I & $P=0.271$ & $P=0.049^{* *}$ & $P=0.000^{* * *}$ & $P=0.000^{* * *}$ \\
\hline 4. Citrus aurantium & $P=0.000^{* * *}$ & $P=0.008^{* * *}$ & $P=0.271$ & /I & $P=0.362$ & $P=0.001^{* * *}$ & $P=0.000^{* * *}$ \\
\hline 5. Olea europea & $P=0.000^{* * *}$ & $P=0.000^{* * *}$ & $P=0.049^{* *}$ & $P=0.362$ & /I & $P=0.010^{* * *}$ & $P=0.000^{* * *}$ \\
\hline 6. Shaded pavement & $P=0.000^{* * *}$ & $P=0.000^{* * *}$ & $P=0.000^{* * *}$ & $P=0.001^{* * *}$ & $P=0.010^{* * *}$ & /I & $P=0.044^{* *}$ \\
\hline 7. Sunlit pavement & $P=0.000^{* * *}$ & $P=0.000^{* * *}$ & $P=0.000^{* * *}$ & $P=0.000^{* * *}$ & $P=0.000^{* * *}$ & $P=0.044^{* *}$ & /I \\
\hline
\end{tabular}

***P: Statistically highly significant difference.

**P: Statistically significant difference.

P: Statistically non significant difference.

the pine $(P$. pinea), which is a characteristic species of the Mediterranean conifer.

Furthermore there is a quantitative correlation between various values of ETc and the different temperatures measured under the trees. The curve in Fig. 10 to the comparison of the value of evaporation (ET) in different tree species with the temperature (T) that develops under each trees which measured. It appears that the temperature under the different species of trees decreases with the increase of evaporation that appears in the 10 figure.

\section{Discussion}

According to the measurements that were made, it was clear that evapotranspiration of plants influences their micro-environment by increasing the humidity of the dry summer atmosphere the conditions of planted regions are more pleasant and thermic comfortable, as well as the discomfort index decreases perceptibly.

This becomes comprehensible according to the measurements. Plants with a high level of evapotranspiration have the most thermal comfortable micro-environment as well as the lowest Discomfort Index $(D I)$. below:

The main conclusions from the research project are listed

- The results show that the tree in the study that was most effective in the reduction of DI was the Ficus species (a tropical plant) that has the highest amount of evapotranspiration and the descending order of effectiveness was shown to be fig $>$ pine $>$ palm $>$ bitter orange $>$ olive.

- DI is small for plants that produced high levels of relative humidity (e.g. Ficus) and DI increased as relative humidity decreased. The olive is associated with the largest $D I$ for all the study plants.

From this observation we can draw useful conclusions about the dual role of relative humidity in determining the DI value.
Relative humidity is a factor in the equation used to calculate the value of DI and when relative humidity increases, DI increases. It has been shown also that all the measurements of temperature made in the shade of plants gave lower values than those made in the shade of non-natural materials. Similar results founded from a previous study Georgi, Zafeiriadis (2006) [8], that has been made under the foliage of several plants at parks of Thessaloniki city. The evapotranspiration of plants increases the relative humidity and contributes indirectly to the reduction of temperature and, consequently, to the decreased value of DI. Therefore, the indirect positive contribution of relative humidity to the reduction of DI is more important than the direct negative contribution.

Consequently, the DI and the evapotranspiration are two reversely proportional values.

Finally it is proved that there is a quantitative correlation between various values of ETc and the different temperatures measured under the trees. As it is known evaporation is expressed in $\mathrm{mm}$ per unit of time (day) and it expresses the quantity of water that is lost from a covered with vegetation surface of soil in certain time in units of height of water. According to Bertaki (2001) [27] at influence evaporation accordingly are weather parameters and factors of vegetation. In this case the weather parameters are same because the measurements occurred in the same region. Hence what changes in the calculation of evaporation is the type of vegetation. According to Moffat and Schiller (1981) [33] the more important mechanism via the trees contribute in the reduction of high temperatures in the cities is evaporation. Therefore from the quantity of energy which a plant needs in order to cope with the high degree of evaporation likely it exceeds the one which it is provided by the received solar radiation. Thus is drawn energy, from the atmospheric heat and the reflected energy of this heat, received from the trees causing the atmospheric reduction of temperature [34]? Accordingly it appears that the temperature under the different species of trees decreases with the increase of evaporation that appears in the curve (Fig. 10).

Table 10

Results of comparison between averages by pairs ( $t$-test): Comparison between averages of relative humidity by pairs of different micro-environments by the $t$-test.

\begin{tabular}{|c|c|c|c|c|c|c|c|}
\hline & 1. Ficus nitida & 2. Pinus pinea & 3. Phoenix canariensis & 4. Citrus aurantium & 5. Olea europea & 6. Shaded pavement & 7. Sunlit pavement \\
\hline 1. Ficus nitida & $1 /$ & $P=0.645$ & $P=0.660$ & $P=0.404$ & $P=0.032^{* *}$ & $P=0.003^{* * *}$ & $P=0.005^{* * *}$ \\
\hline 2. Pinus pinea & $P=0.645$ & /I & $P=0.995$ & $P=0.689$ & $P=0.082$ & $P=0.008^{* * *}$ & $P=0.015^{* *}$ \\
\hline 3. Phoenix canariensis & $P=0.660$ & $P=0.995$ & /I & $P=0.695$ & $P=0.092$ & $P=0.010^{* * *}$ & $P=0.018^{* *}$ \\
\hline 4. Citrus aurantium & $P=0.404$ & $P=0.689$ & $P=0.695$ & /I & $P=0.199$ & $P=0.027^{* *}$ & $P=0.044^{* *}$ \\
\hline 5. Olea europea & $P=0.032^{* *}$ & $P=0.082$ & $P=0.092$ & $P=0.199$ & II & $P=0.277$ & $P=0.375$ \\
\hline 6. Shaded pavement & $P=0.003^{* * *}$ & $P=0.008^{* * *}$ & $P=0.010^{* * *}$ & $P=0.027^{* *}$ & $P=0.277$ & /I & $P=0.869$ \\
\hline 7. Sunlit pavement & $P=0.005^{* * *}$ & $P=0.015^{* *}$ & $P=0.018^{* *}$ & $P=0.044^{* *}$ & $P=0.375$ & $P=0.869$ & /I \\
\hline
\end{tabular}

***P: Statistically highly significant difference.

**P: Statistically significant difference.

P: Statistically non significant difference. 
Table 11

Results of comparison between averages by pairs ( $t$-test): Comparison between averages of $D I$ by pairs of different micro-environments by the $t$-test.

\begin{tabular}{|c|c|c|c|c|c|c|c|}
\hline & 1. Ficus nitida & 2. Pinus pinea & 3. Phoenix canariensis & 4. Citrus aurantium & 5. Olea europea & 6. Shaded pavement & 7. Sunlit pavement \\
\hline 1. Ficus nitida & /I & $P=0.046^{* *}$ & $P=0.000^{* * *}$ & $P=0.000^{* * *}$ & $P=0.000^{* * *}$ & $P=0.000^{* * *}$ & $P=0.000^{* * *}$ \\
\hline 2. Pinus pinea & $P=0.046^{* *}$ & /I & $P=0.032^{* *}$ & $P=0.001^{* * *}$ & $P=0.000^{* * *}$ & $P=0.000^{* * *}$ & $P=0.000^{* * *}$ \\
\hline 3. Phoenix canariensis & $P=0.000^{* * *}$ & $P=0.032^{* *}$ & /I & $P=0.220$ & $P=0.139$ & $P=0.000^{* * *}$ & $P=0.000^{* * *}$ \\
\hline 4. Citrus aurantium & $P=0.000^{* * *}$ & $P=0.001^{* * *}$ & $P=0.220$ & /I & $P=0.792$ & $P=0.003^{* * *}$ & $P=0.000^{* * *}$ \\
\hline 5. Olea europea & $P=0.000^{* * *}$ & $P=0.000^{* * *}$ & $P=0.139$ & $P=0.792$ & /I & $P=0.006^{* * *}$ & $P=0.000^{* * *}$ \\
\hline 6. Shaded pavement & $P=0.000^{* * *}$ & $P=0.000^{* * *}$ & $P=0.000^{* * *}$ & $P=0.003^{* * *}$ & $P=0.006^{* * *}$ & /I & $P=0.004^{* * *}$ \\
\hline 7. Sunlit pavement & $P=0.000^{* * *}$ & $P=0.000^{* * *}$ & $P=0.000^{* * *}$ & $P=0.000^{* * *}$ & $P=0.000^{* * *}$ & $P=0.004^{* * *}$ & /I \\
\hline
\end{tabular}

***P: Statistically highly significant difference.

**P: Statistically significant difference.

P: Statistically non significant difference.

\section{Conclusion and recommendations}

Concerning the documentation of theoretical part, the case study that we investigated and the results that were exported and formulated above, we have led to the following observations:

The existence of plants in the spaces of a town can improve in a satisfactory level the DI because of their functions of Shading and Evapotranspiration. For the plant selections should be taken into consideration the relative humidity of each species because $D I$ is small for plants that produced high levels of relative humidity (e.g. ficus) and $D I$ increased as relative humidity decreased.

$\checkmark$ the temperature under the different species of trees decreases with the increase of evaporation

$\checkmark$ Even though technology has progressed in the design of devices used for protection from the sun, such as heat reflecting glass panes, air conditioners and fans known to us all, as well as awnings for shading manufactured by various materials that are used to reflect and prevent the heat, the evaluation of green spaces in the city outlines its current situation and the necessity of increasing urban spaces for improvement of the urban microclimate and the quality of life of its residents. The presence of vegetation improves the microclimate in the interior of the city, and optimises the conditions of thermal comfort. This emerged from the results of the bioclimatic measurements that were made in the area of study to determine the effect of shade from tree foliage if anyone contemplates the environmental and ecological benefit from the aid of green spaces in the cities, the cost of maintenance and installation (which is proportional to the extent) is considerably low (Table 4).

The following table shows the cost of installation of various well known devices and systems for cooling and sun protection as well as the planting of a tree (indicatively the plane tree) in combination with their duration of life.

$\checkmark$ the progressive increase and completion of planting in the area of study can affect the urban landscape and the microclimate positively and improve the existing conditions According to Mansfield [12] (2002) the overall annual benefits of a tree results from energy saving, the improvement of the quality of air, the reduction in the levels of carbon dioxide and the absorbing of rainwater.

According to Mansfield et al. [12] (2002), Sailor [36] (1997) the increasing the forest cover in a city reduces summertime heat more that it increases wintertime cold. Huang et al. [37] (1990) said that planting trees located around residential structures may reduce both cooling and heating costs due to reduced summer heating and a wind-shielding effect.

Consequently, the results of the present study are useful because the consumption of energy, mainly during the warm months, for air conditioning, can be decreased provided that the trees contribute to air cooling and to the above mentioned reports made by Nguyen [35] (2005).

$\checkmark$ the choice of suitable types of trees for the city environment according each species' contribution to the reduction of DI as well as its morphological and other characteristics, the age of each kind and its resistibility in the climatic conditions that prevail in each region will facilitate the adoption of planting schemes suitable to the peculiarities of the city.

$\checkmark$ the improvement of the city environment through the introduction of new trees' rows and parks creation will encourage people to walk under their shade. This improvement may be an incentive for less future use of the car as a means of transport.

$\checkmark$ it is essential for a list to be compiled that will describe the suitability of each tree species according to its contribution to the reduction of $D I$; in combination with its other characteristics, classification of each tree species into the appropriate category could be possible.

$\checkmark$ the choice of species should be made in order to satisfy the criteria that reflect the requirements of planting; i.e. aesthetics, functional, ecological, and bioclimatic

$\checkmark$ the growth of the knowledge base can help research concerning the professions of landscape architecture, ecology and urban planning that should be fulfilled when establishing plantings in the city, and particularly along the streets and the parks that are the heart of urban areas.

$\checkmark$ Finally it is examined an area of $100 \mathrm{~m}^{2}, 8$ trees can be planted within $5 \mathrm{~m}$ from each other to achieve desirable thermal comfort throughout the year (Fig. 11),creating a more pleasant environment for the visitor and ,at the same time, providing protection from solar radiation and decreasing the temperature up to $3.1{ }^{\circ} \mathrm{C}$, as it appears from the measurements that have been done, improving the microclimate, something that is desired if we consider that as long as the temperature goes up the thermal comfort decreases and that $32{ }^{\circ} \mathrm{C}$ boarders on medical alarm (Table 2). On the contrary, four spraying fans can be placed in the same area of $100 \mathrm{~m}^{2}$ (Fig. 12), the operations of which serve only this space and create a hostile environment without providing any protection other than the temperature reduction proportional to that provided by trees with the difference that their cost is far greater. Finally in the same space of $100 \mathrm{~m}^{2}$, there can be placed an awning (Fig. 13) which will serve only as protection from the sun and minimal reduction of temperature, provided that special tent fabric is use the cost of which increases by far. Table 5 shows the differences at cost benefit data of three different cooling installations in a space of $100 \mathrm{~m}^{2}$. It is obvious that planting 8 trees can be cheaper than fan spray and than the use of awning.

Fig. 11 shows that in a space of $100 \mathrm{~m}^{2}, 8$ trees can be placed, creating a more pleasant environment to the visitor and at the same time providing protection from solar radiation 
Fig. 12 shows that in a space of $100 \mathrm{~m}^{2}, 4$ spraying fans can be placed, which serve only this space and create a hostile environment without providing some other type of protection

Fig. 13 shows that in a space of $100 \mathrm{~m}^{2}$, an awning that would cover $100 \mathrm{~m}^{2}$ can be installed the cost of which is increased and the only benefit that it offers is the protection from the solar radiation with a minimal reduction in temperature.

Given the assumptions made, it can be concluded that trees perform better, from an environmental point of view, than the traditional cooling systems for outdoors.

We believe that this research is important, and that it could be used in other cities with all the known species that are used for planting in the urban green areas, and the results could be grouped with those of other case studies in cities with similar climatic and meteorological conditions.

Tables 6-8 show the values for each plant in contributing to the reduction of $D I$, and environmental parameters that are not desirable, will constitute a simple and useful tool for planting plans and the improvement of urban environments and in other regions of the Mediterranean zone.

\section{Acknowledgments}

The authors wish to thank associate professor Menelaos Triantafillou at University of Cincinnati, School of Planning for his prereview and his corrections in grammar, English and structure of the paper and Achilleas Kampouris for his Technical Assistance for the present paper.

\section{References}

[1] Giannas S. Bioclimatic principals of town-planning design in Environmental design of towns and open space. Patra: Hellenic Open University; 2001. pp. 177-207.

[2] Aravadinos A. Uses of earth - zoning and town planning - the levels of design in Introduction to natural and human environment. Patra: Hellenic Open University; 1999. pp. 117-128, 408.

[3] Herrington LP. Vegetation and thermal environments of human settlements environments of human Settlements. In: Proceedings of the Conference: trees and forest for human Settlements. Centre for Urban Forestry Studies, University of Toronto; 1978. p. 372-9.

[4] Akbari H, Taha H. The impact of trees and white surfaces on residential heating and cooling energy use in four Canadian cities. Energy 1992;17(2):141-9.

[5] Thom EC. The distribution index. Weatherise 1959;12(2):57-60.

[6] Balafoutis CJ, Arseni-Papadimitriou A, Chantsaridis P. Allocation of discomfort index at the Greek space. In: Proceedings of 4th panhellenic geographical conference which there was at 12,13,14. Greek Geographic Association; 1998; October 1995. p. 440-52.

[7] Georgi, N, The ecological, aesthetic and functional behaviour of trees in the city of Thessaloniki Ph thesis, Aristotle university of Thessaloniki, Thessaloniki; 2000. p. 199.

[8] Georgi NJ, Zafeiriadis K. The impact of park trees on microclimate in urban areas. Urban Ecosystems Journal 2006;9:195-209. doi:10.1007/S 11252-0068590-9.

[9] Prevezanos S. Cardiogram in a building. ECOTECH Journal (October), CAPITAL: SAVING OF ENERGY, http://www.ecotec.gr/index.php; 2007.

[10] Georgiou K. Flora and vegetation: plants and attributes as for their use for the improvement of built environment. In: Introduction in natural and human environment, vol. I. Patra: Hellenic Open University; 1999. p.313.

[11] Dimoudi A, Nikolopoulou M. Vegetation in the urban environment: microclimatic analysis and benefits. Energy and Buildings 2003;5:9-76.
[12] Mansfield CA, Subhrendu K, Pattanayak, McDow W, McDonald R, Halpin P. Shades of green: measuring the value of urban forests in the housing market; 2002. p. $1-26$.

[13] Dombrow J, Rodriguez M, Sirmans CF. The market value of mature trees in single-family housing markets. The Appraisal Journal 2000;1:39-43.

[14] Simpson JR, McPherson EG. Simulation of tree shade impacts on residential energy use for space conditioning in sacramento. Atmospheric Environment 1998;32(1):69-74.

[15] Morancho AB. A hedonic valuation of urban green areas. Planning, 2003 Landscape and Urban Planning 2003;66(1):35-41. 15 December 2003.

[16] Bolitzer B, Netusil NR. The impact of open spaces on property values in Portland, Oregon. J Environ Manage 2000;59(3):185-93.

[17] Tyrvainen L, Miettinen A. Property prices and urban forest amenities. J Environ Econ Manage 2000;39:205-23.

[18] Zoulia I, Santamouris M, Dimoudi A. Monitoring the effect of urban green areas on the heat island in Athens. Environ Monit Assess 2008;2008:1-18.

[19] Dimoudi A. Urban design. In: Santamouris M, Assimakopoulos D, editors. Passive cooling of buildings. London: James \& James Science; 1996. p. 95-128.

[20] Santamouris M. The role of green spaces. In: Santamouris M, editor. Energy and climate in the urban built environment. London: James \& James Science; 2001. p. $145-59$.

[21] Souch CA, Souch C. The effect of trees on summertime below canopy urban climates: a case study Bloomington, Indiana. J Arboriculture 1993;19(5):303-12.

[22] U.S. Geological Survey. The water cycle: evapotranspiration. Retrieved 12 June 2007 from, http://ga.water.usgs.gov/edu/watercycleevapotranspiration.html; 2007.

[23] Simpson JR, McPherson EG. Tree planting to optimize energy and $\mathrm{CO}_{2}$ benefits. In: Kollin C, editor. Investing in Natural Capital. Washington D.C: Proceedings of the 2001 National Urban Forest Conference; 2001. September 5-8., 2001.

[24] Mitchell VG, Cleugh HA, Grimmond CSB, Xu J. 4Linking urban water balance and energy balance models to analyse urban design options. Hydrological Processes 2007;22(16):2891-900.

[25] ETo Calculator - Evapotranspiration from a reference surface (CD-ROM) ISBN: 9789251062661, FAO; 2009.

[26] . Allen Richard G, Pereira Luis S, Raes Dirk, Smith Martin. FAO-Crop evapotranspiration - Guidelines for computing crop water requirements. 1998 Series title: FAO Irrigation and Drainage Papers - 56, X0490/E. Rome: FAO Irrigation and drainage paper 56, Food and Agriculture Organization of the United Nations; 1998.

[27] Bertaki M. Evapotranspiration and needs at water of principal crops of prefecture of Chania, Master dissertation in Agricultural University of Athens July; 2001.

[28] Papazafiriou Z. Principles and practice of irrigation, Thessaloniki (in Greek), 1984.

[29] Hargreaves GH, Samani ZA. Reference crop evapotranspiration from temperature. Appl Eng in Agric ASAE 1985.

[30] Taha HG, Akbari H, Rosenfeld AH. Vegetation canopy microclimate: a field project in Davis, California. Berkley, CA: Lawrence Berkley in Davis, Laboratory Report-24593; 1988.

[31] Parker JR. The impact of vegetation on air conditioning consumption. Controlling summer heat island'. In: Akbari H, Garbesi K, Martien P, editors. Proceedings of the workshop on: saving energy and reducing atmospheric pollution by controlling summer heat island. Barkley, California: University of California; 1989. p. 42-52. pp.

[32] Balafoutis CJ, Maheras P. Geographical distribution and grouping of bioclimatic types in Greece related to air Enthalpy. Zeitschrift Fur Meteorological 1986;36(4):259-64. pp.

[33] Moffat AS, Schiler M. Landscape design that saves energy. New York. New York: William Morrow and Company, Inc; 1981.

[34] Jones HG. Plants and microclimate. Cambridge: Cambridge University Press; 1992.

[35] Nguyen A. A benefit - cost analysis of ten urban landscaping trees in Berkley. CA Drubin/Barnes Lab; 2005. pp. 1-26.

[36] Sailor DJ. Simulations of annual degree day Impacts of urban Vegetative Augmentation. Atmospheric Environment 1997;32(1):43-52.

[37] Huang YJ, Akbari H, Taha H. The wind-shielding and shading effects of trees on residential heating and cooling requirements. ASHREA Transactions 1990;96:1403-11.

[38] Suat I and Dorota Z. H. - Evapotranspiration: Potential or Reference?; University of Florida. 